Marquette University

e-Publications@Marquette

Biomedical Engineering Faculty Research and

Publications

Biomedical Engineering, Department of

$7-2014$

\title{
Effect of Lowest Instrumented Vertebra on Trunk Mobility in Patients With Adolescent Idiopathic Scoliosis Undergoing a Posterior Spinal Fusion
}

\author{
Ubong I. Udoekwere \\ Marquette University \\ Joseph Krzak \\ Shriners Hospitals for Children \\ Adam Graf \\ Shriners Hospitals for Children \\ Sahar Hassani \\ Shriners Hospitals for Children \\ Sergey Tarima \\ Medical College of Wisconsin
}

See next page for additional authors

Follow this and additional works at: https://epublications.marquette.edu/bioengin_fac

Part of the Biomedical Engineering and Bioengineering Commons

\footnotetext{
Recommended Citation

Udoekwere, Ubong I.; Krzak, Joseph; Graf, Adam; Hassani, Sahar; Tarima, Sergey; Riordan, Mary; Sturm, Peter F.; Hammerberg, Kim W.; Gupta, Purnendu; Anissipour, Alireza K.; and Harris, Gerald F., "Effect of Lowest Instrumented Vertebra on Trunk Mobility in Patients With Adolescent Idiopathic Scoliosis Undergoing a Posterior Spinal Fusion" (2014). Biomedical Engineering Faculty Research and Publications. 239.

https://epublications.marquette.edu/bioengin_fac/239
} 


\section{Authors}

Ubong I. Udoekwere, Joseph Krzak, Adam Graf, Sahar Hassani, Sergey Tarima, Mary Riordan, Peter F. Sturm, Kim W. Hammerberg, Purnendu Gupta, Alireza K. Anissipour, and Gerald F. Harris 


\title{
Effect of Lowest Instrumented Vertebra on Trunk Mobility in Patients with Adolescent Idiopathic Scoliosis Undergoing a Posterior Spinal Fusion
}

\author{
Ubong I. Udoekwere \\ College of Engineering, Marquette University, \\ Milwaukee, WI \\ Joseph J. Krzak
}

Motion Analysis Laboratory, Shriners Hospitals for Children, Chicago, IL

Adam Graf

Motion Analysis Laboratory, Shriners Hospitals for Children, Chicago, IL

Sahar Hassani

Motion Analysis Laboratory, Shriners Hospitals for Children, Chicago, IL

Sergey Tarima

Division of Biostatistics, Medical College of Wisconsin,

Milwaukee, WI 
NOT THE PUBLISHED VERSION; this is the author's final, peer-reviewed manuscript. The published version may be accessed by following the link in the citation at the bottom of the page.

\author{
Mary Riordan \\ Motion Analysis Laboratory, Shriners Hospitals for Children, \\ Chicago, IL \\ Peter F. Sturm \\ Division of Orthopaedic Surgery, \\ Cincinnati Children's Hospital Medical Center, \\ Cincinnati, $\mathrm{OH}$ \\ Kim W. Hammerberg \\ Motion Analysis Laboratory, Shriners Hospitals for Children, \\ Chicago, IL \\ Pumendu Gupta \\ Motion Analysis Laboratory, Shriners Hospitals for Children, \\ Chicago, IL \\ Alireza K. Anissipour \\ College of Osteopathic Medicine, Midwestern University, \\ Downers Grove, IL \\ Gerald F. Harris \\ College of Engineering, Marquette University, \\ Milwaukee, WI \\ Motion Analysis Laboratory, Shriners Hospitals for Children, \\ Chicago, IL \\ College of Health Sciences, Physical Therapy Program, \\ Midwestern University, \\ Downers Grove, IL
}

\title{
Abstract
}

Study Design. Prospective.

Objectives. The goal of this study was to evaluate the effect of posterior spinal fusion surgery terminating at different lowest instrumented vertebrae (LIV) on trunk mobility in individuals with adolescent idiopathic scoliosis (AIS). 
NOT THE PUBLISHED VERSION; this is the author's final, peer-reviewed manuscript. The published version may be accessed by following the link in the citation at the bottom of the page.

Summary of Background Data. Posterior spinal fusion with instrumentation is the standard surgical technique employed in AIS for correcting spine deformities with Cobb angles exceeding $50^{\circ}$. Surgical correction of curve deformity reduces trunk mobility and range of motion. However, conflicting findings from previous studies investigating the impact of different LIV levels on the reduction in trunk mobility after surgery have been reported.

Methods. The study was designed as a prospective study with 47 patients ( 7 males and 40 females) with AIS who underwent posterior spinal fusion.

Patients were classified into 5 groups based on their surgical LIV level (ie, T12, L1, L2, L3, and L4). Trunk flexion-extension (sagittal plane), lateral bending (coronal plane), and axial rotation (transverse plane) kinematics were assessed during preoperative, 1 year postoperative, and 2 years postoperative evaluation visits.

Results. There were postoperative reductions of $41 \%, 51 \%$, and $59 \%$ in trunk range of motion in the sagittal, coronal, and transverse planes, respectively $(p<.0001)$. A trend toward greater postoperative reductions in peak forward flexion at more distal LIVs was observed $(p=.04)$.

Conclusions. Fusion reduces trunk mobility in the sagittal, coronal, and transverse planes. More distal LIV fusions limit peak forward flexion to a greater extent which is considered clinically significant. After fusion, the reductions seen in axial rotation, lateral bending, and backward extension do not differ significantly at more distal LIVs.

Keywords: Adolescent idiopathic scoliosis, Posterior spinal fusion, Trunk mobility, Range of motion, Lowest instrumented vertebra

\section{Introduction}

Posterior spinal fusion with instrumentation (PSFI) is the standard of care for correcting spine deformities in individuals with adolescent idiopathic scoliosis (AIS) and Cobb angles exceeding $50^{\circ} . \underline{1} ; \underline{2} ; \underline{3}$ Long-term results suggest that PSFI can effectively limit curve progression and ensure spine stability for individuals with AIS. $4 ; \underline{i} ; \underline{6} ; \underline{7}$

Although PSFI effectively corrects spine deformity, postoperative limitations in intersegmental mobility among the fused vertebral levels ultimately result in reduction of overall trunk mobility (ie, forward flexion, backward extension, bilateral lateral bending, and bilateral axial rotation). ${ }^{4 ;} \underline{\underline{5}} \underline{6} ; \underline{i} ; \underline{8} ; \underline{9} ; \underline{10}$ Furthermore, some studies suggest that loss in trunk mobility may cause an increased compensatory mobility at unfused segments adjacent to the fusion, which may eventually lead to spinal degeneration of unfused segments and low back pain. $\underline{4} ; \underline{6} ; \underline{2} ; \underline{9} ; \underline{10} ; \underline{11} ; \underline{12}$

Currently, few studies have attempted to accurately measure reduction in trunk mobility after fusion. Recent studies have commonly

Spine Deformity, Vol 2, No. 4 (July 2014): pg. 291-300. DOI. This article is (C) Elsevier and permission has been granted for this version to appear in e-Publications@Marquette. Elsevier does not grant permission for this article to be further copied/distributed or hosted elsewhere without the express permission from Elsevier. 
employed either inclinometers or motion capture techniques to accurately quantify trunk mobility reduction after surgical fusion. $\underline{8} ; \underline{i} ; \underline{i 0}$ However, these studies are not without limitations, which range from being retrospective to using heterogeneous sampling of different fusion techniques (ie, anterior spinal fusion, posterior spinal fusion, or both), and to using unvalidated or nonstandardized models of kinematic computation for determining spine range of motion (ROM). $; \underline{8} ; \underline{10} ; \underline{13}$

Despite the obvious reduction in trunk mobility after fusion, even fewer clinical studies conclusively address how surgical choice of the lowest instrumented vertebra (LIV) influences the amount of reduction. The direct impact of LIV level on postoperative trunk mobility in patients with AIS has not been conclusively demonstrated. $\underline{8} ; \underline{9} ; \underline{0} ; \underline{13} ; \underline{14} ; \underline{15} ; \underline{16}$ Today, many clinicians are still faced with difficult questions posed by families who inquire about changes to expect after fusion, particularly how reductions in trunk mobility vary with LIV over time. The purpose of this study was to quantitatively examine and compare trunk mobility in individuals with AIS undergoing posterior spinal fusion surgery at different LIVs preoperatively and at 1 and 2 years postoperatively. We hypothesized that PSFI terminating at a more distal LIV will result in greater reductions in sagittal, coronal, and transverse plane trunk kinematics during trunk bending tasks while standing. Specifically, we expected that fusion to the distal lumbar segments would result in greater reductions in kinematic peaks and overall trunk ROM than fusion terminating at proximal lumbar and thoracic segments.

\section{Materials and Methods}

\section{Study design and participants}

This was a prospective study performed on a sample of convenience between October 2007 and August 2012 at a single specialized pediatric orthopedic institution. A consecutive series of 120 patients had a posterior spinal fusion during that time, of which 47 patients ( 7 male and 40 female) agreed to participate in this institutional review board-approved study as the scoliosis group. Thirty-nine patients made the 1-year follow-up visit (mean, 1.15

Spine Deformity, Vol 2, No. 4 (July 2014): pg. 291-300. DOI. This article is @ Elsevier and permission has been granted for this version to appear in e-Publications@Marquette. Elsevier does not grant permission for this article to be further copied/distributed or hosted elsewhere without the express permission from Elsevier. 
years; range, 0.8-1.5 years) and 36 made the 2-year visit (mean, 2.2 years; range, $1.8-3.4$ years). All patients and a legal guardian gave signed consent before testing. To be included, patients had a diagnosis of AIS and a Cobb angle $>50^{\circ}$ (group mean Cobb angle, $56^{\circ} \pm 12^{\circ}$ ). The average age at the time of the PSFI was 15.3 years (range, $11.9-$ 18.9 years). Patients were classified into 5 groups based on their surgical LIV level (T12, L1, L2, L3, and L4). Five patients were fused to an LIV of T12, 4 to L1, 8 to L2, 15 to L3, and 15 to L4. Of 47 patients, 44 had upper instrumented vertebrae between T2 and T4. Patients were excluded if they had a neuromuscular pathology, were unable to walk or stand independently, were pregnant, or required a fusion outside the LIV groups listed above. All patients were given the same basic postoperative rehabilitation instructions that were to be mobilized out of bed on the first day and to increase activity as tolerated. Table 1 lists demographic data for all patients in this study.

Table 1. Demographic patient data including gender, age at surgery, weight, height, fusion levels, and lowest instrumented vertebra.

\begin{tabular}{|c|c|c|c|c|c|c|c|}
\hline Patient & $\begin{array}{l}\text { Lowest } \\
\text { instrumented } \\
\text { vertebra }\end{array}$ & Gender & Age & $\begin{array}{c}\text { Weight, } \\
\text { kg }\end{array}$ & $\begin{array}{c}\text { Height, } \\
\text { cm }\end{array}$ & $\begin{array}{l}\text { Fusion } \\
\text { levels }\end{array}$ & $\begin{array}{l}\text { Lenke } \\
\text { class }\end{array}$ \\
\hline 01 & L3 & $\mathrm{F}$ & 15.8 & 71.1 & 103.2 & $\mathrm{~T} 11-\mathrm{L} 3$ & $6(B)$ \\
\hline 02 & L3 & $\mathrm{F}$ & 13.0 & 45.0 & 154.0 & T3-L3 & $5(C)$ \\
\hline 03 & L3 & $\mathrm{F}$ & 14.7 & 53.2 & & T4-L3 & $6(C)$ \\
\hline 04 & $\mathrm{~T} 12$ & $\mathrm{~F}$ & 13.5 & 62.6 & 168.9 & T3-T12 & $1(\mathrm{C})$ \\
\hline 05 & $\mathrm{~T} 12$ & $\mathrm{~F}$ & 18.3 & 54.0 & 162.6 & T2-T12 & $4(C)$ \\
\hline 06 & L4 & $F$ & 13.2 & 60.5 & 170.0 & T3-L4 & $6(C)$ \\
\hline 07 & L3 & $M$ & 15.9 & 64.1 & 167.0 & T3-L3 & $3(C)$ \\
\hline 08 & L3 & $F$ & 15.4 & 89.7 & 165.0 & T3-L3 & $2(C)$ \\
\hline 09 & L4 & $\mathrm{F}$ & 19.9 & 46.4 & 157.5 & T2-L4 & $1(\mathrm{C})$ \\
\hline 10 & L2 & $F$ & 10.6 & 28.1 & 134.6 & $\mathrm{~T} 2-\mathrm{L} 2$ & $1(\mathrm{C})$ \\
\hline 11 & L3 & $\mathrm{F}$ & 14.4 & 40.8 & 161.3 & T2-L3 & $3(B)$ \\
\hline 12 & L3 & M & 16.2 & 53.2 & 166.4 & T3-L3 & $3(C)$ \\
\hline 13 & L2 & $\mathrm{F}$ & 14.2 & 37.7 & 156.9 & T2-L2 & $4(C)$ \\
\hline 14 & L3 & $\mathrm{F}$ & 17.8 & 50.3 & 157.5 & T3-L3 & $1(\mathrm{C})$ \\
\hline 15 & L3 & $\mathrm{F}$ & 15.1 & 52.3 & 170.2 & T10-L3 & $5(C)$ \\
\hline 16 & L1 & $F$ & 14.7 & 54.5 & 162.5 & T3-L1 & $3(B)$ \\
\hline 17 & L3 & $M$ & 15.0 & 50.9 & 152.5 & T2-L3 & $1(\mathrm{C})$ \\
\hline 18 & L4 & $F$ & 11.9 & 65.9 & 161.9 & T4-L4 & $3(\mathrm{C})$ \\
\hline 19 & L4 & $F$ & 15.6 & 65.0 & 160.0 & T4-L4 & $6(C)$ \\
\hline 20 & L3 & $\mathrm{F}$ & 15.9 & 90.9 & 156.0 & T2-L3 & $3(C)$ \\
\hline 21 & L2 & $M$ & 16.8 & 80.9 & 175.5 & T3-L2 & \\
\hline
\end{tabular}

Spine Deformity, Vol 2, No. 4 (July 2014): pg. 291-300. DOI. This article is (C) Elsevier and permission has been granted for this version to appear in e-Publications@Marquette. Elsevier does not grant permission for this article to be further copied/distributed or hosted elsewhere without the express permission from Elsevier. 


\begin{tabular}{|c|c|c|c|c|c|c|c|}
\hline Patient & $\begin{array}{l}\text { Lowest } \\
\text { instrumented } \\
\text { vertebra }\end{array}$ & Gender & Age & $\begin{array}{c}\text { Weight, } \\
\text { kg }\end{array}$ & $\begin{array}{c}\text { Height, } \\
\text { cm }\end{array}$ & $\begin{array}{l}\text { Fusion } \\
\text { levels }\end{array}$ & $\begin{array}{l}\text { Len } \\
\text { clas }\end{array}$ \\
\hline 22 & L2 & $M$ & 15.5 & 84.5 & 175.0 & $\mathrm{~T} 2-\mathrm{L} 2$ & $5(C)$ \\
\hline 23 & L1 & $\mathrm{F}$ & 14.6 & 52.3 & 157.0 & T4-L1 & $1(C)$ \\
\hline 24 & L3 & $\mathrm{F}$ & 12.3 & 47.7 & 155.0 & T3-L3 & $1(C)$ \\
\hline 25 & L3 & $\mathrm{F}$ & 15.0 & 44.5 & 155.0 & T2-L3 & $2(C)$ \\
\hline 26 & L3 & $\mathrm{F}$ & 12.8 & 34.8 & 143.0 & T2-L3 & $6(C)$ \\
\hline 27 & L4 & $\mathrm{F}$ & 13.1 & 56.6 & 159.0 & T2-L4 & $3(C)$ \\
\hline 28 & $\mathrm{~T} 12$ & $\mathrm{~F}$ & 14.8 & 45.4 & 160.0 & $\mathrm{~T} 4-\mathrm{T} 12$ & $2(B)$ \\
\hline 29 & L1 & $\mathrm{F}$ & 17.4 & 57.2 & 165.1 & T2-L1 & $3(C)$ \\
\hline 30 & L4 & $\mathrm{F}$ & 17.4 & 54.1 & 176.0 & T4-L4 & $3(C)$ \\
\hline 31 & L1 & $\mathrm{F}$ & 13.0 & 55.0 & 165.0 & T3-L1 & $3(C)$ \\
\hline 32 & $\mathrm{~T} 12$ & $\mathrm{~F}$ & 18.8 & 61.6 & 165.6 & T3-T12 & $3(C)$ \\
\hline 33 & L2 & $\mathrm{F}$ & 15.7 & 53.2 & 160.0 & T2-L2 & $4(C)$ \\
\hline 34 & L4 & $\mathrm{F}$ & 16.5 & 71.3 & 170.0 & T2-L4 & $2(C)$ \\
\hline 35 & L4 & $M$ & 15.0 & 47.3 & 167.0 & T3-L4 & $3(C)$ \\
\hline 36 & $\mathrm{~T} 12$ & $\mathrm{~F}$ & 12.0 & 63.6 & 158.7 & T3-T12 & $3(C)$ \\
\hline 37 & L2 & $\mathrm{F}$ & 16.9 & 53.6 & 166.0 & T2-L2 & $3(C)$ \\
\hline 38 & L4 & $\mathrm{F}$ & 14.2 & 50.0 & 164.0 & T3-L4 & $3(C)$ \\
\hline 39 & L2 & $\mathrm{F}$ & 17.6 & 49.5 & 162.0 & T4-L2 & $3(C)$ \\
\hline 40 & L2 & $\mathrm{F}$ & 16.9 & 55.5 & 154.0 & T3-L2 & $1(C)$ \\
\hline 41 & L4 & $F$ & 12.9 & 44.5 & 142.0 & T3-L4 & $6(C)$ \\
\hline 42 & L4 & $\mathrm{F}$ & 15.7 & 53.6 & 160.0 & T3-L4 & $3(C)$ \\
\hline 43 & L4 & $M$ & 16.1 & 60.1 & 168.9 & T3-L4 & $3(C)$ \\
\hline 44 & L4 & $\mathrm{F}$ & 12.7 & 61.7 & 167.0 & T3-L4 & $2(C)$ \\
\hline 45 & L3 & $\mathrm{F}$ & 16.9 & 50.5 & 160.0 & T11-L3 & $5(C)$ \\
\hline 46 & L4 & $\mathrm{F}$ & 16.8 & 52.7 & 164.4 & T4-L4 & $6(C)$ \\
\hline 47 & L4 & $\mathrm{F}$ & 15.0 & 52.2 & 154.0 & T4-L4 & \\
\hline
\end{tabular}

F, female; M, male.

\section{Surgery and radiographic assessment}

Posterior spinal fusion with instrumentation surgery was performed on all patients. Radiographic assessment was performed preoperatively and at postoperative years 1 and 2 to determine Cobb angle, Lenke curve type, trunk shift (in centimeters), sagittal balance (in centimeters), and pelvic incidence. $\underline{17} ; \underline{18} ; \underline{19} ; \underline{20} ; \underline{21}$ All radiographic measurements were obtained from a single orthopedic surgeon.

\section{Trunk movement data collection}


To prepare for protocol testing, all subjects were instrumented with 20 reflective markers placed in accordance with the Full Body Plug-in-Gait model (Vicon Motion Systems, Oxford, UK). 22; $23 ; 24$ This model consists of a single trunk segment with 6 markers placed over the spinous process of $\mathrm{C} 7$ and T10 vertebrae, xyphoid process, suprasternal notch, and bilateral acromion process. The motion of the trunk segment was measured in relation to the pelvis to control for pelvic motion compensations and isolate the measurement to the trunk.

This version of the Plug-in-Gait model excludes the head and arm segments. Three pelvic markers were also placed on the right and left anterior superior iliac spine, and sacrum. The remaining 11 markers were placed on the lower extremities to capture gait motion, which is not reported in this study. A Vicon MX system with 14 cameras (Oxford Metrics, Oxford, UK) was used to capture marker trajectories during the trunk movement protocol.

\section{Trunk movement protocol}

All participants performed a trunk movement protocol preoperatively to assess functional ROM. All study participants were instructed to stand in a comfortable upright position with the feet flat on the ground and knees straight, and to actively move the trunk to the maximum end range of motion in the sagittal, coronal, and transverse planes. Participants performed 6 active trunk motions: trunk forward flexion and backward extension (sagittal), right and left lateral bending (coronal), and right and left axial rotation (transverse) (Fig. 1). After each trunk motion, participants were asked to return to their comfortable upright posture. Two trials were collected for each motion and averaged together.

Spine Deformity, Vol 2, No. 4 (July 2014): pg. 291-300. DOI. This article is @ Elsevier and permission has been granted for this version to appear in e-Publications@Marquette. Elsevier does not grant permission for this article to be further copied/distributed or hosted elsewhere without the express permission from Elsevier. 
NOT THE PUBLISHED VERSION; this is the author's final, peer-reviewed manuscript. The published version may be accessed by following the link in the citation at the bottom of the page.

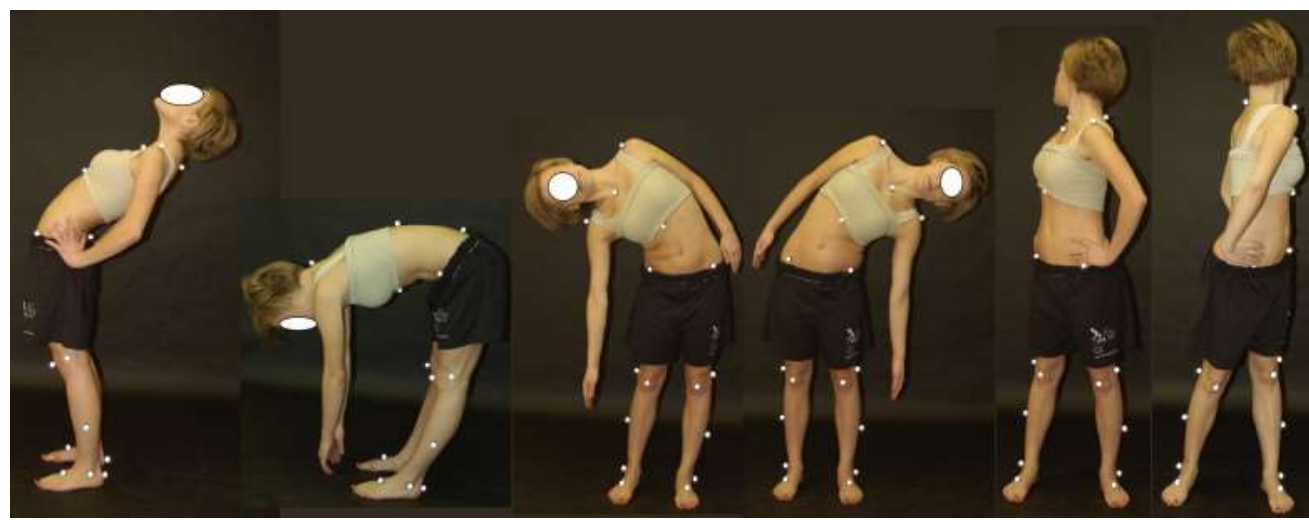

Fig. 1. (From left to right) Subject performing peak backward extension, forward flexion, peak lateral bending to the left and right, and peak axial rotation left and right.

\section{Follow-up evaluation}

Participants performed the same trunk movement protocol at 1 year postoperatively (mean, 1.2 years; range, $0.8-1.6$ years) and 2 years postoperatively (mean, 2.2 years; range, $1.8-3.4$ years).

\section{Outcome measures}

The researchers measured the motion of the trunk segment relative to the pelvis using the Vicon MX motion caption system during protocol execution to determine trunk kinematic peaks and overall trunk ROM in the sagittal, coronal, and transverse planes.

\section{Statistical analysis}

Statistical comparisons of trunk kinematic peaks and overall trunk ROM in the sagittal, coronal, and transverse planes were performed using individual mixed effects analyses of variance. The authors analyzed the fixed effects of LIV (T12-L4) and time (preoperatively and postoperative years 1 and 2) and the interaction of time and LIV to test the whether a more distal LIV would result in greater reductions in postoperative sagittal, coronal, and transverse plane trunk kinematic peaks and ROM. They used random effects of the multiple trials per participant and the multiple visits in each model to account for within-person dependence because each study participant was assessed multiple times during each visit. When a 
significant main effect was observed, post hoc pairwise comparisons were performed to identify significant differences. To limit the number of false discovery findings associated with multiple comparisons, an alpha level of .01 was used for statistical significance. All statistical analyses were done with R 2.13 statistical software (R Foundation for Statistical Computing, Vienna, Austria).

\section{Results}

\section{Effect of surgery on trunk kinematics}

There was a postoperative reduction in all trunk kinematic measures for trunk motion in all 3 planes $(p<.0001)$. In the first postoperative evaluation visit, there was an average reduction of $16^{\circ}$ $(57 \%)$ in peak axial rotation to the left, $15^{\circ}(61 \%)$ in average peak axial rotation to the right, and $31^{\circ}(59 \%)$ in average axial rotation ROM. Postoperative mean reductions of $24^{\circ}(56 \%), 17^{\circ}(45 \%)$, and $41^{\circ}(51 \%)$ were also observed in peak lateral bending to the left, to the right, and lateral bending ROM, respectively. Similarly, peak forward flexion, peak backward extension, and overall flexionextension ROM decreased postoperatively by averages of $28^{\circ}(62 \%)$, $11^{\circ}(22 \%)$, and $40^{\circ}(41 \%)$, respectively. Interestingly, there was an increase in the average right peak lateral bending, lateral bending ROM, and right axial rotation of $3^{\circ}(p=.0005), 6^{\circ}(p=.0002)$, and $3^{\circ}(p=.0046)$ respectively, from the first postoperative visit to the second one.

\section{Postoperative effect on trunk kinematics among LIV groups}

No significant interaction effects of time and LIV were identified. Individuals with surgical fusion to the distal lumbar segments did not have statistically greater reductions in kinematic peaks or overall trunk ROM than individuals whose instrumentation terminated at proximal lumbar and thoracic segments. A trend toward greater postoperative reductions in peak forward flexion at more distal LIVs was observed ( $p$ $=.04$ ) but this finding also did not achieve statistical significance at a $=.01$. Fig. 2 , Fig. $3 ;$ Fig. 4 and Table 2 show the trunk kinematic peaks and overall trunk ROM for sagittal flexion-extension, coronal

Spine Deformity, Vol 2, No. 4 (July 2014): pg. 291-300. DOI. This article is ( Elsevier and permission has been granted for this version to appear in e-Publications@Marquette. Elsevier does not grant permission for this article to be further copied/distributed or hosted elsewhere without the express permission from Elsevier. 
NOT THE PUBLISHED VERSION; this is the author's final, peer-reviewed manuscript. The published version may be accessed by following the link in the citation at the bottom of the page.

lateral bending, and transverse axial rotation for each LIV group over the preoperative and postoperative visits.
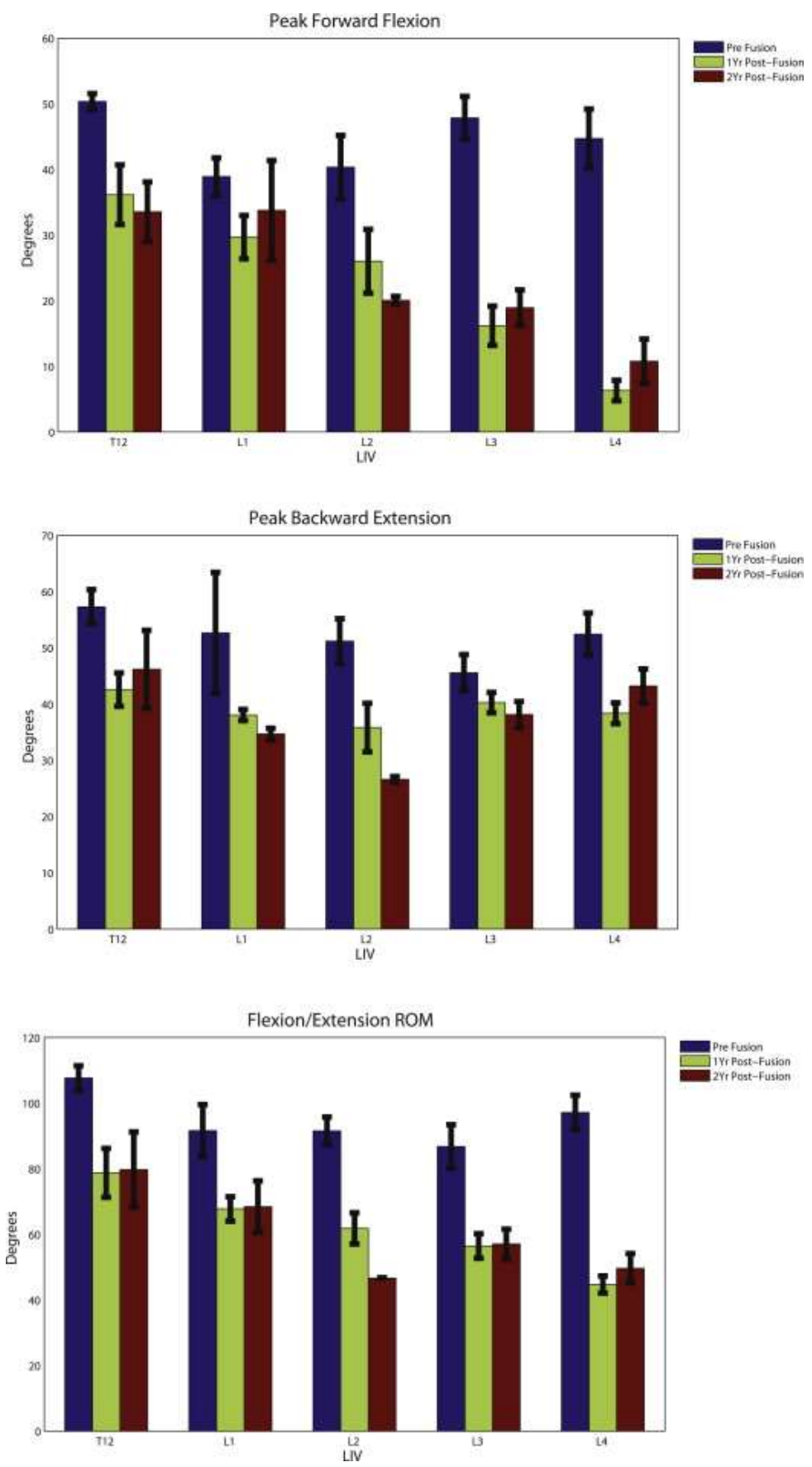

Fig. 2. Lowest instrumented vertebra group averages and standard error bars of kinematic peaks and range of motion for trunk motion in the sagittal plane at the preoperative and 1- and 2-year postoperative visits. Plots depict peaks for forward flexion motion (top) and backward extension motion (middle), and ROM for overall flexion-extension motion (bottom). 
NOT THE PUBLISHED VERSION; this is the author's final, peer-reviewed manuscript. The published version may be accessed by following the link in the citation at the bottom of the page.
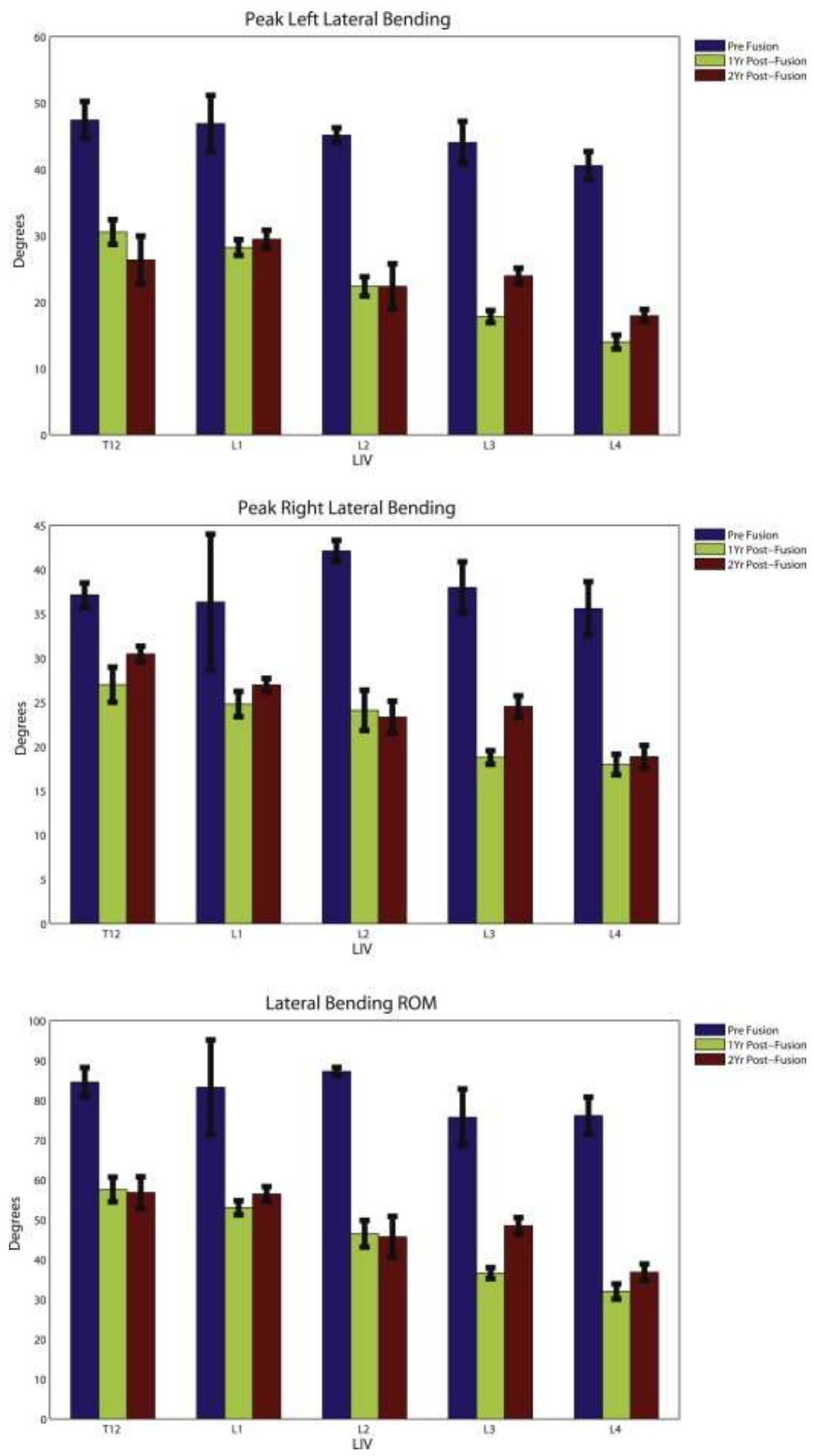

Fig. 3. Lowest instrumented vertebra group averages and standard error bars of kinematic peaks and range of motion for trunk motion in the coronal plane at the preoperative and 1- and 2-year postoperative visits. Plots depict peaks for lateral bending motion to the left (top) and right (middle), and ROM for overall lateral bending motion (bottom).

Spine Deformity, Vol 2, No. 4 (July 2014): pg. 291-300. DOI. This article is (C) Elsevier and permission has been granted for this version to appear in e-Publications@Marquette. Elsevier does not grant permission for this article to be further copied/distributed or hosted elsewhere without the express permission from Elsevier. 
NOT THE PUBLISHED VERSION; this is the author's final, peer-reviewed manuscript. The published version may be accessed by following the link in the citation at the bottom of the page.
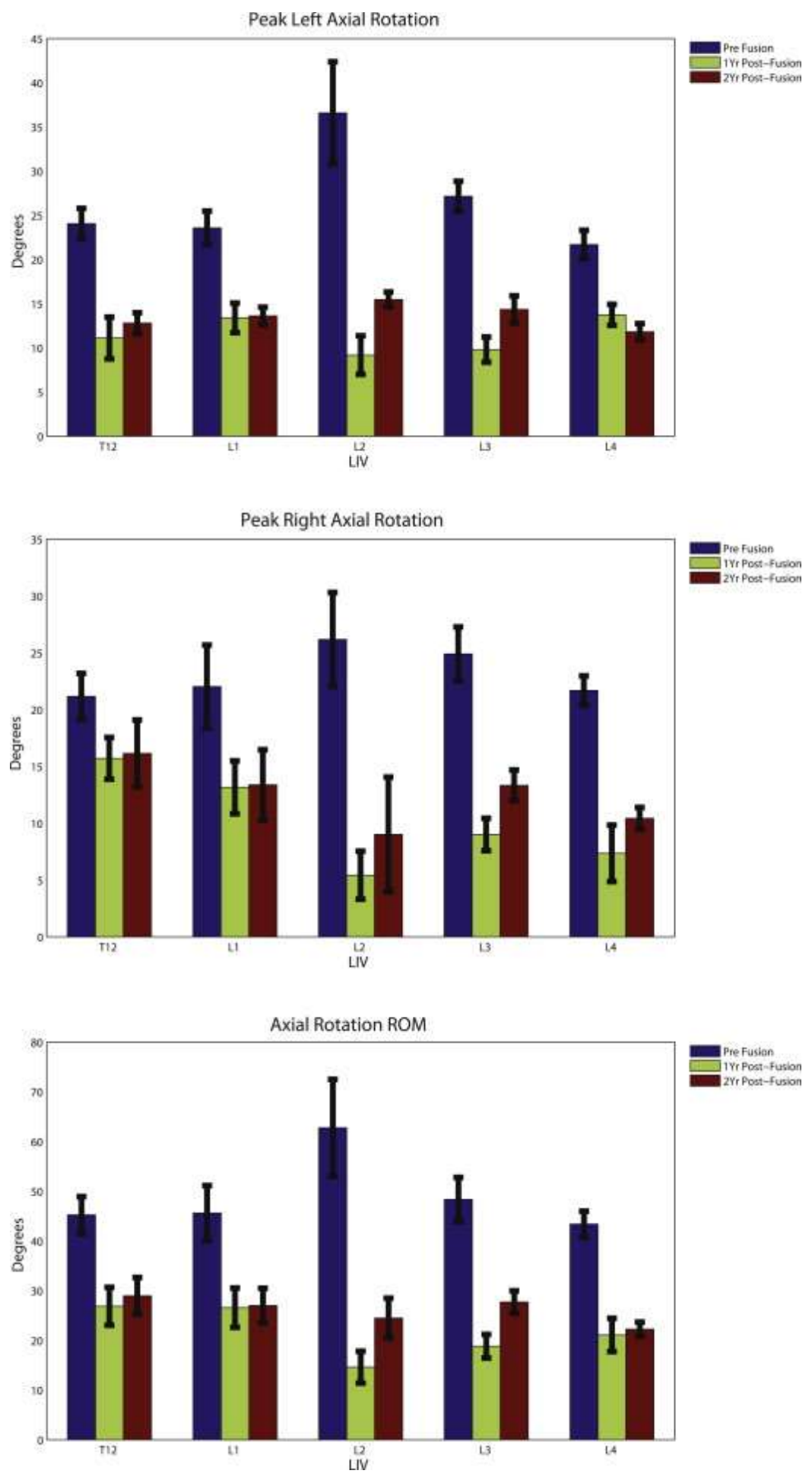

Fig. 4. Lowest instrumented vertebra group averages and standard error bars of kinematic peaks and range of motion for trunk motion in the transverse plane at the preoperative and 1- and 2-year postoperative visits. Plots depict peaks for axial rotation motion to the left (top) and right (middle), and ROM for overall axial rotation motion (bottom).

Spine Deformity, Vol 2, No. 4 (July 2014): pg. 291-300. DOI. This article is (C) Elsevier and permission has been granted for this version to appear in e-Publications@Marquette. Elsevier does not grant permission for this article to be further copied/distributed or hosted elsewhere without the express permission from Elsevier. 
NOT THE PUBLISHED VERSION; this is the author's final, peer-reviewed manuscript. The published version may be accessed by following the link in the citation at the bottom of the page.

Table 2. Trunk motion across LIV Pre, 1 , and 2 years post surgery.

Degrees of sagittal motion

\begin{tabular}{|c|c|c|c|c|c|c|c|c|c|c|c|c|c|c|c|}
\hline & & T12 & & & L1 & & & $\mathbf{L 2}$ & & & L3 & & & L4 & \\
\hline & $\mathbf{P r}$ & P1 & $\mathbf{P 2}$ & Pr & P1 & $\mathbf{P 2}$ & Pr & P1 & $\mathbf{P 2}$ & Pr & P1 & $\mathbf{P 2}$ & $\operatorname{Pr} \mathbf{P}$ & P1 & \\
\hline Forward flexion & 50 & 36 & 34 & 393 & 303 & 34 & 40 & 26 & 20 & 481 & 16 & 19 & & & 11 \\
\hline Backward extension & 57 & 43 & 46 & 53 & 383 & 35 & 51 & 36 & 27 & 464 & 403 & 38 & 523 & 384 & 43 \\
\hline Range of Motion & 108 & 79 & 80 & 92 & $68 \epsilon$ & 68 & 92 & 62 & 47 & 875 & 565 & 57 & 974 & 455 & 50 \\
\hline
\end{tabular}

Degrees of coronal motion

\begin{tabular}{|c|c|c|c|c|c|c|c|c|c|c|c|c|}
\hline & T12 & & & -1 & & L2 & & & L3 & & L4 & \\
\hline & Pr P1 & $\mathbf{P 2}$ & $\operatorname{Pr} \mathbf{P 1}$ & 1 P2 & Pr & P1 & P2 & Pr $\mathbf{P}$ & P1 P2 & $2 \mathrm{Pr}$ & P1 & P2 \\
\hline Left I & 4731 & 26 & 4728 & 829 & 452 & 222 & 22 & 441 & 1824 & 41 & 14 & 18 \\
\hline Right lateral bending & 3727 & 30 & 3625 & 527 & 422 & 242 & 23 & 381 & 1925 & 36 & 18 & 19 \\
\hline Range of motion & 8558 & 57 & 8353 & 356 & 874 & $46<$ & 46 & 763 & 3749 & 76 & 32 & 37 \\
\hline
\end{tabular}

Degrees of transverse motion

\begin{tabular}{|c|c|c|c|c|c|c|c|c|c|c|c|c|c|c|c|}
\hline & & T12 & & & $\mathbf{L 1}$ & & & L2 & & & L3 & & & L4 & \\
\hline & $\mathbf{P r}$ & P1 & $\mathbf{P 2}$ & $\mathbf{P r}$ & P1 & P2 & $\mathbf{P r}$ & P1 & P2 & $\mathbf{P r}$ & P1 & P2 & $\mathbf{P r}$ & P1 & $\mathbf{P 2}$ \\
\hline $\begin{array}{l}\text { Left axial } \\
\text { rotation }\end{array}$ & 24 & 11 & 13 & 24 & 13 & 14 & 37 & 9 & 15 & 27 & 10 & 14 & 22 & 14 & 12 \\
\hline $\begin{array}{l}\text { Right axial } \\
\text { rotation }\end{array}$ & 21 & 16 & 16 & 22 & 13 & 13 & 26 & 5 & 9 & 25 & 9 & 13 & 22 & 7 & 10 \\
\hline $\begin{array}{l}\text { Range of } \\
\text { motion }\end{array}$ & 45 & 27 & 29 & 46 & 27 & 27 & 63 & 15 & 24 & 48 & 19 & 28 & 43 & 21 & 22 \\
\hline
\end{tabular}

\section{Radiographic assessment}

Table 3 describes preoperative and postoperative radiographic data for all patients in this study. The mean Cobb angle was reduced from $55.7^{\circ} \pm 12^{\circ}$ at the preoperative evaluation visit to $22.8^{\circ} \pm 8^{\circ}$

Spine Deformity, Vol 2, No. 4 (July 2014): pg. 291-300. DOI. This article is C Elsevier and permission has been granted for this version to appear in e-Publications@Marquette. Elsevier does not grant permission for this article to be further copied/distributed or hosted elsewhere without the express permission from Elsevier. 
NOT THE PUBLISHED VERSION; this is the author's final, peer-reviewed manuscript. The published version may be accessed by following the link in the citation at the bottom of the page.

and $23.0^{\circ} \pm 9^{\circ}$ at the postoperative visits in years 1 and 2 , respectively.

Table 3. Radiographic data for all patients.

\begin{tabular}{|c|c|c|c|c|}
\hline & $\begin{array}{c}\text { Cobb } \\
\text { (degrees) }\end{array}$ & $\begin{array}{c}\text { Trunk shift, } \\
\text { cm }\end{array}$ & $\begin{array}{c}\text { Sagittal } \\
\text { balance, } \mathrm{cm}\end{array}$ & $\begin{array}{l}\text { Pelvic incidence } \\
\text { (degrees) }\end{array}$ \\
\hline Preoperative & $56 \pm 12$ & $1.1 \pm 1.5$ & $-1.3 \pm 2.6$ & $53 \pm 13$ \\
\hline $\begin{array}{l}\text { Postoperative } 1 \\
\text { year }\end{array}$ & $23 \pm 8$ & $1.1 \pm 1.4$ & $-3.2 \pm 2.6$ & $53 \pm 13$ \\
\hline $\begin{array}{l}\text { Postoperative } 2 \\
\text { years }\end{array}$ & $23 \pm 9$ & $0.9 \pm 0.8$ & $-3.0 \pm 3.0$ & $54 \pm 13$ \\
\hline
\end{tabular}

\section{Discussion}

The central finding of this study is that PSFI results in reduced trunk mobility in all motion planes $(p<.0001)$. Distal LIV fusions limit postoperative peak forward flexion more than proximal fusions ( $p$ $=.04$ ) (Table 4 ). The limitation in peak forward flexion with distal LIV was considered clinically significant and trended toward statistical significance, although it did not achieve it at $a=.01$. Reductions in peak forward flexion after surgery were $28 \%$ at T12, $24 \%$ at L1, 36\% at $\mathrm{L} 2,66 \%$ at $\mathrm{L} 3$, and $86 \%$ at $\mathrm{L} 4$. Changes in peak flexion from postoperative year 1 to year 2 were not statistically significant ( $p$ $=.5$ ). Of particular interest was the increased peak flexion range during the second postoperative year in the L3 and L4 LIV groups. This may represent a compensatory change in the unfused segments.

Table 4. Average peak forward flexion for each lowest instrumented vertebra at preoperative and 1- and 2-year postoperative visits.

\begin{tabular}{llll}
$\begin{array}{c}\text { Lowest } \\
\text { instrumented } \\
\text { vertebra }\end{array}$ & \multicolumn{1}{c}{$\begin{array}{c}\text { Preoperative } \\
\text { (degrees) }\end{array}$} & $\begin{array}{c}\text { Postoperative 1 } \\
\text { year (degrees) }\end{array}$ & $\begin{array}{c}\text { Postop } \\
\text { years }\end{array}$ \\
T12 & $50 \pm 4$ & $36 \pm 13$ & $34 \pm 11$ \\
L1 & $39 \pm 6$ & $30 \pm 8$ & $34 \pm 19$ \\
L2 & $40 \pm 15$ & $26 \pm 15$ & $20 \pm 1$ \\
L3 & $48 \pm 16$ & $16 \pm 15$ & $19 \pm 13$ \\
L4 & $45 \pm 21$ & $6 \pm 7$ & $11 \pm 15$
\end{tabular}

Data are shown as means \pm standard deviation.

The current study reports no difference in postoperative reductions in axial rotation, lateral bending peaks, or ROM between proximal and distal LIV. A previous study on the effect of fusion on

Spine Deformity, Vol 2, No. 4 (July 2014): pg. 291-300. DOI. This article is @ Elsevier and permission has been granted for this version to appear in e-Publications@Marquette. Elsevier does not grant permission for this article to be further copied/distributed or hosted elsewhere without the express permission from Elsevier. 
spine mobility in individuals with AIS reported comparable findings that suggest no significant correlation between LIV and reduced ROM in axial rotation or lateral bending. $\stackrel{-8}{ }$ Because the anatomical orientation of the thoracic facets permits axial rotation, it is intuitive that fusions in this region reduce motion.

Results in similar studies report contradictory findings regarding the relationship between LIV and reductions in forward flexion after fusion. Engsberg et al. $\underline{8}$ showed no statistical correlation between LIV and postoperative loss in forward flexion ROM. On the other hand, Sanchez-Raya et al. $\underline{9}$ demonstrated that distally extending LIV is correlated moderately with reduced forward flexion mobility. Winter et al. $\underline{13}$ showed that loss in forward flexion is only correlated with an LIV at L4. In the current study, the authors chose a conservative alpha level of .01 to limit the number of false discovery findings. However, they detected a trend toward a decrease in peak forward flexion as the LIV moved distally at a $p$ value of .04 (Fig. 2A).

The average reduction in axial rotation ROM after spinal fusion in the current study was comparable to that reported by Engsberg et al. $\underline{8}$ in a similar study. On the other hand, the postoperative reductions in forward flexion and lateral bending ROM in their study were about half of what was seen in our study. $\underline{8}$ One possible reason for the variances is that different kinematic computational models were used. The study by Engsberg et al. quantified spine mobility preoperatively and postoperatively by implementing a model that captured relative motion between multiple regions of the spinal column using markers placed at C7, T4, T10, and L4. Although the kinematic approach of placing markers on the spine is appealing for directly assessing spine mobility, $\underline{8} ; \underline{25} ; \underline{26}$ it is not a standard model, which makes it more difficult to implement in other clinical settings. The reliability of identifying or tracking spinous processes is also known to be variable. $27 ; \underline{28 ; \underline{29}}$ The kinematic model chosen for the current study was a standard Plug-in Gait model that was used to capture the relative motion between the thorax segment and the pelvic segment to represent trunk mobility. The practice of using of trunk mobility as a fair representation of spine mobility has been demonstrated in other studies. $\underline{9} ; \underline{10} ; \underline{23} ; \underline{30}$ Furthermore, the standard Plug-in Gait model used in the current study was described and validated. $\underline{22}$ Although there is no consensus or universal technique for recording spine kinematics, the

Spine Deformity, Vol 2, No. 4 (July 2014): pg. 291-300. DOI. This article is (C) Elsevier and permission has been granted for this version to appear in e-Publications@Marquette. Elsevier does not grant permission for this article to be further copied/distributed or hosted elsewhere without the express permission from Elsevier. 
choice to use a standard validated kinematic model makes model implementation less complex and more applicable to other clinical settings.

The current study attempted to address limitations in past studies $\underline{8} ; \underline{9} ; \underline{10} ; \underline{14} ; \underline{15} ; \underline{16}$ by 1 ) maintaining homogeneity in surgical technique (PSFI only) and LIV classification, 2) increasing sample sizes in the LIV groups, and 3) using a validated, standard model for kinematic computation. A limitation in this study is that the kinematic model used considered the trunk to be a rigid segment created from reflective markers placed above the LIVs. Direct assessment of intersegmental trunk and spine mobility would be preferable, although the authors are unaware of any such model that has been validated.

This study used a standardized, validated biomechanical model on a group of patients with AIS and a PSFI with clearly defined LIVs and found $41 \%, 51 \%$, and $59 \%$ postoperative reductions in flexionextension ROM, lateral bending ROM, and axial rotation ROM, respectively. More distal LIV fusions limit peak forward flexion to a greater extent, which is considered clinically significant. Reductions in axial rotation, lateral bending, and backward extension are seen with all LIVs and do not differ significantly with more distal fusions. These findings are of clinical significance to the physician counseling patients and families regarding the loss of lumbar motion after PSFI for AIS. Surgeons can use this information to aid in preoperative planning to achieve a balance between maximizing curve correction and restoring coronal compensation, versus preserving lumbar motion. Future work should focus on collecting data on LIV groups with lower power and the validation of a kinematic model that would increase the segments in the trunk.

\section{References}

1 K.J. Noonan, S.L. Weinstein, W.C. Jacobson, et al. Use of the Milwaukee brace for progressive idiopathic scoliosis. J Bone Joint Surg Am, 78 (1996), pp. 557-567

2S.L. Weinstein, I.V. Ponseti. Curve progression in idiopathic scoliosis. J Bone Joint Surg Am, 65 (1983), pp. 447-455

3S.L. Weinstein. Idiopathic scoliosis: natural history. Spine (Phila Pa 1976), 11 (1986), pp. 780-783

Spine Deformity, Vol 2, No. 4 (July 2014): pg. 291-300. DOI. This article is @ Elsevier and permission has been granted for this version to appear in e-Publications@Marquette. Elsevier does not grant permission for this article to be further copied/distributed or hosted elsewhere without the express permission from Elsevier. 
${ }^{4}$ B.J. Bartie, J.E. Lonstein, R.B. Winter. Long-term follow-up of adolescent idiopathic scoliosis patients who had Harrington instrumentation and fusion to the lower lumbar vertebrae: is low back pain a problem? Spine (Phila Pa 1976), 34 (2009), pp. E873-E878

5 D.K. Collis, I.V. Ponseti. Long-term follow-up of patients with idiopathic scoliosis not treated surgically. J Bone Joint Surg Am, 51 (1969), pp. 425-445

6.V.V. Grouw, C.I. Nadel, R.J. Weierman, et al. Long term follow-up of patients with idiopathic scoliosis treated surgically: a preliminary subjective study. Clin Orthop Relat Res, 117 (1976), pp. 197-201

IA. Moskowitz, J.H. Moe, R.B. Winter, et al. Long-term follow-up of scoliosis fusion. J Bone Joint Surg Am, 62 (1980), pp. 364-376

8].R. Engsberg, L.G. Lenke, A.K. Reitenbach, et al. Prospective evaluation of trunk range of motion in adolescents with idiopathic scoliosis undergoing spinal fusion surgery. Spine (Phila Pa 1976), 27 (2002), pp. 1346-1354

9]. Sanchez-Raya, J. Bago, F. Pellise, et al. Does the lower instrumented vertebra have an effect on lumbar mobility, subjective perception of trunk flexibility, and quality of life in patients with idiopathic scoliosis treated by spinal fusion? J Spinal Disord Tech, 25 (2012), pp. 437-442

10B. Wilk, L.A. Karol, C.E. Johnston, et al. The effect of scoliosis fusion on spinal motion: a comparison of fused and nonfused patients with idiopathic scoliosis. Spine (Phila Pa 1976), 31 (2006), pp. 309-314

11C. Gotze, U.R. Liljenqvist, A. Slomka, et al. Quality of life and back pain: outcome 16.7 years after Harrington instrumentation. Spine (Phila Pa 1976), 27 (2002), pp. 1456-1463 discussion 1463-4

12R.K. Pratt, R.G. Burwell, A.A. Cole, et al. Patient and parental perception of adolescent idiopathic scoliosis before and after surgery in comparison with surface and radiographic measurements. Spine (Phila Pa 1976), 27 (2002), pp. 1543-1550 discussion 1551-2

$\underline{13}$ R.B. Winter, P. Carr, H.L. Mattson. A study of functional spinal motion in women after instrumentation and fusion for deformity or trauma. Spine (Phila Pa 1976), 22 (1997), pp. 1760-1764

14 H.A. King, J.H. Moe, D.S. Bradford, et al. The selection of fusion levels in thoracic idiopathic scoliosis. J Bone Joint Surg Am, 65 (1983), pp. $1302-1313$

15 M.A. Erickson, D.M. Baulesh. Lowest instrumented vertebra selection in AIS. J Pediatr Orthop, 31 (2011), pp. S69-S76

16]. Takahashi, P.O. Newton, V.L. Ugrinow, et al. Selective thoracic fusion in adolescent idiopathic scoliosis: factors influencing the selection of the optimal lowest instrumented vertebra. Spine (Phila Pa 1976), 36 (2011), pp. 1131-1141

Spine Deformity, Vol 2, No. 4 (July 2014): pg. 291-300. DOI. This article is (C) Elsevier and permission has been granted for this version to appear in e-Publications@Marquette. Elsevier does not grant permission for this article to be further copied/distributed or hosted elsewhere without the express permission from Elsevier. 
NOT THE PUBLISHED VERSION; this is the author's final, peer-reviewed manuscript. The published version may be accessed by following the link in the citation at the bottom of the page.

${ }^{17}$ H. Kim, H.S. Kim, E.S. Moon, et al. Scoliosis imaging: what radiologists should know. Radiographics, 30 (2010), pp. 1823-1842

${ }_{18}^{18}$ B.S. Richards, A. Scaduto, K. Vanderhave, et al. Assessment of trunk balance in thoracic scoliosis. Spine (Phila Pa 1976), 30 (2005), pp. 1621-1626

${ }^{19}$ R.M. Ali, O. Boachie-Adjei, B.A. Rawlins. Functional and radiographic outcomes after surgery for adult scoliosis using third-generation instrumentation techniques. Spine (Phila Pa 1976), 28 (2003), pp. 1163-1169 discussion 1169-70

20W. Skalli, R.D. Zeller, L. Miladi, et al. Importance of pelvic compensation in posture and motion after posterior spinal fusion using $C D$ instrumentation for idiopathic scoliosis. Spine (Phila Pa 1976), 31 (2006), pp. E359-E366

21].M. Mac-Thiong, H. Labelle, M. Charlebois, et al. Sagittal plane analysis of the spine and pelvis in adolescent idiopathic scoliosis according to the coronal curve type. Spine (Phila Pa 1976), 28 (2003), pp. 1404-1409

22E.M. Gutierrez, A. Bartonek, Y. Haglund-Akerlind, et al. Centre of mass motion during gait in persons with myelomeningocele. Gait and Posture, 18 (2003), pp. 37-46

23]. Romkes, W. Peeters, A.M. Oosterom, et al. Evaluating upper body movements during gait in healthy children and children with diplegic cerebral palsy. J Pediatr Orthop B, 16 (2007), pp. 175-180

${ }^{24}$ R.B. Davis, S. Ounpuu, D. Tyburski, et al. A gait analysis data collection and reduction technique. Human Movement Science, 10 (1991), pp. 575587

${ }^{25}$ C. Frigo, R. Carabalona, M. Dalla Mura, et al. The upper body segmental movements during walking by young females. Clin Biomech (Bristol, Avon), 18 (2003), pp. 419-425

26].R. Engsberg, L.G. Lenke, M.L. Uhrich, et al. Prospective comparison of gait and trunk range of motion in adolescents with idiopathic thoracic scoliosis undergoing anterior or posterior spinal fusion. Spine (Phila Pa 1976), 28 (2003), pp. 1993-2000

${ }^{27}$ A. Leardini, L. Chiari, U. Della Croce, et al. Human movement analysis using stereophotogrammetry-Part 3: soft tissue artifact assessment and compensation. Gait and Posture, 21 (2005), pp. 212-225

28 M.A. Seffinger, W.I. Najm, S.I. Mishra, et al. Reliability of spinal palpation for diagnosis of back and neck pain-A systematic review of the literature. Spine (Phila Pa 1976), 29 (2004), pp. E413-E425

29 M.J. Stochkendahl, H.W. Christensen, J. Hartvigsen, et al. Manual examination of the spine: a systematic critical literature review of reproducibility. J Manipulative Physiol Ther, 29 (2006), pp. 475-485

Spine Deformity, Vol 2, No. 4 (July 2014): pg. 291-300. DOI. This article is (C) Elsevier and permission has been granted for this version to appear in e-Publications@Marquette. Elsevier does not grant permission for this article to be further copied/distributed or hosted elsewhere without the express permission from Elsevier. 
NOT THE PUBLISHED VERSION; this is the author's final, peer-reviewed manuscript. The published version may be accessed by following the link in the citation at the bottom of the page.

30M.T. Hresko, M. Mesiha, K. Richards, et al. A comparison of methods for measuring spinal motion in female patients with adolescent idiopathic scoliosis. J Pediatr Orthop, 26 (2006), pp. 758-763

Author disclosures: UIU (grants from Helen Kay Charitable Trust, grants from Hainer Foundation, grants from DePuy Synthesis); JJK (grants from DePuy Synthesis, grants from Hainer Foundation, grants from the Helen Kay Charitable Trust); AG (grants from DePuy Synthesis, grants from Hainer Foundation, grants from the Helen Kay Charitable Trust); SH (grants from Helen Kay Charitable Trust, grants from Hainer Foundation, grants from DePuy Synthesis); ST (grants from Helen Kay Charitable Trust, grants from Hainer Foundation, grants from DePuy Synthesis); MR (grants from Helen Kay Charitable Trust, grants from Hainer Foundation, grants from DePuy Synthesis); PFS (consultant for DePuy Spine and Orthopediatrics; shareholder with Pioneer Surgical); KWH (grants from Helen Kay Charitable Trust, grants from Hainer Foundation, grants from DePuy Synthesis); PG (grants from Helen Kay Charitable Trust, grants from Hainer Foundation, grants from DePuy Synthesis); AKA (grants from Helen Kay Charitable Trust, grants from Hainer Foundation, grants from DePuy Synthesis); GFH (grants from Helen Kay Charitable Trust, grants from Hainer Foundation, grants from DePuy Synthesis).

This study was supported by grants from DePuy Synthesis, the Hainer Foundation, and the Helen Kay Charitable Trust, US Department of Education NIDRR Grant H133P100008, and Grant UL1RR031973 from the Clinical and Translational Science Award (CTSA) program of the National Center for Research Resources (NCRR) and the National Center for Advancing Translational Sciences (NCATS).

Corresponding author. Shriners Hospitals for Children, 2211 N. Oak Park Ave, Chicago, IL 60707, USA. Tel.: (773) 385-5458; fax: (773) 385-5459.

Spine Deformity, Vol 2, No. 4 (July 2014): pg. 291-300. DOI. This article is (C) Elsevier and permission has been granted for this version to appear in e-Publications@Marquette. Elsevier does not grant permission for this article to be further copied/distributed or hosted elsewhere without the express permission from Elsevier. 